\section{An Exploration of Supports for Increasing Classroom Physical Activity within Elementary Schools}

\author{
Hannah G. Calvert ${ }^{a,}{ }^{*}$, Julianne A. Wenner ${ }^{b}$, Lindsey Turner ${ }^{c}$
}

\begin{tabular}{ll}
\hline Received: & 14 March 2019 \\
Revised: & 11 June 2019 \\
Accepted: $\quad 26$ June 2019 \\
ISSN: 1307-9298 \\
Copyright (C) IEJEE \\
www.iejee.com
\end{tabular}

DOI: 10.26822/iejee.2019155331

\begin{abstract}
Classroom-based physical activity (CBPA) can significantly benefit students' health and educational outcomes, but many teachers do not utilize CBPA. This study examined teachers' perceptions about the value and impact of several approaches to support CBPA implementation, and teachers' weekly self-reported CBPA use. Interviews were conducted with 35 classroom teachers (including those using and not using CBPA) at two public elementary schools, and CBPA tracking logs were collected on a weekly basis. Interview transcripts were interpreted through key domains within implementation science. On average, teachers reported using one activity every other day. Interview data revealed that utilizing professional collaboration time for peer-to-peer feedback and getting informal support from the school's physical education teacher both have some promise for increasing implementation of CBPA. However, teachers largely felt these strategies were unnecessary. Explicit administrator support was reported by teachers as the most promising mechanism for increasing their CBPA implementation.
\end{abstract}

Keywords: Physical Activity, Classroom, Elementary, Implementation, Administration

\section{Background}

A growing amount of literature continues to demonstrate the value of physical activity (PA) throughout the school day for children (Institute of Medicine [IOM], 2013; Katzmarzyk et al., 2016; Pate et al., 2006). Lengthy bouts of sedentary time adversely impact health outcomes and children's ability to focus in class; conversely, providing opportunities for PA throughout each school day can counter these effects, benefitting both health and academic outcomes (Centers for Disease Control and Prevention [CDC], 2010; Mahar, Murphy, et al., 2006; Rasberry et al., 2011; Tremblay et al., 2011; Webster, Russ, Vazou, Goh, \& Erwin, 2015). Given the detrimental effects of insufficient PA, several organizations have called for schools to provide regular and frequent opportunities for PA during the school day (CDC, 2013; IOM, 2013). The "Whole School, Whole Community, Whole Child" model (Lewallen, Hunt, Potts-Datema, Zaza, \& Giles, 2015) explicitly acknowledges the connections between health and academic outcomes. The model emphasizes that it is crucial for schools to provide a setting in which students can maximize their learning outcomes, which is facilitated by a healthy, safe and supportive environment. A key element involves providing opportunities for PA before, during, and after school.

A widely-utilized strategy for promoting PA involves the development of a Comprehensive School Physical Activity Program (CDC, 2013; Society of Health and Physical Educators [SHAPE] America, 2013) at each school. This acknowledges five elements that create a comprehensive PA-supportive environment, including: a) physical education (PE); b) PA during school; c) PA before and after school; d) staff involvement; and e) family and community engagement. In elementary schools, much research has focused on two opportunities through which students can engage in PA: recess and PE class. Children can accrue substantial during-school PA from these programs (Burns, Brusseau, Fu, Myrer, \& Hannon, 2016; Tudor-Locke, Lee, Morgan, Beighle, \& Pangrazi, 2006) but at the majority of public elementary schools in the United States (US), PE class is not provided daily. In $2009-10$, only $21 \%$ of public elementary schools in the US provided students with PE every day, and $27 \%$ provided students with fewer than 20 minutes of recess per day-or none at all (Turner, Chaloupka, \& Slater, 2012). In other words, students need more PA opportunities on a daily basis. CBPA is not a substitute for $\mathrm{PE}$, which is designed to meet instructional standards for knowledge and skills (SHAPE America, 2015) nor for recess, which serves developmental needs for unstructured play time (American Alliance for Health, Physical Education, Recreation and Dance, 2006). However, CBPA can meet an important need by providing opportunities for brief bouts of PA throughout each day.

Classroom-based physical activity involves the use of brief breaks for PA and/or physically-active lessons that integrate movement into lesson delivery. As such, it meets two key elements of Comprehensive School Physical Activity Programs because it provides students with PA during school, and also facilitates staff involvement. This combination may help to create social norms where it is common for all teachers-not only the PE teacher-to contribute to a culture where PA is valued and supported. CBPA has quantifiable PA and health benefits for students (Bartholomew \& Jowers, 2011; Donnelly \& Lambourne, 2011). Additionally - and perhaps of more interest to educators-CBPA can have educational benefits, including improved attention, time on task, classroom climate, and academic performance (CDC, 2010; Grieco, Jowers, Errisuriz, \& Bartholomew, 2016; Mahar, 2011). Notably, regular CBPA can also improves grades and scores on standardized achievement tests (Hollar et al., 2010; Rasberry et al., 2011), though more research is needed in this area (Singh et al., 2018).

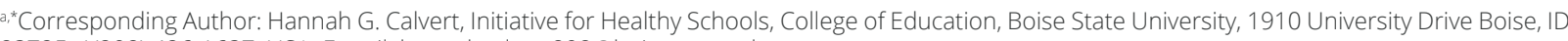
83725, 1(208) 426-1637, USA. E-mail: hannahcalvert898@boisestate.edu

b Julianne A. Wenner, Department of Curriculum, Instruction, and Foundational Studies, College of Education, Boise State University, 1910 University Drive Boise, ID 83725, 1(208) 426-1637, USA. E-mail: juliannewenner@boisestate.edu

c Lindsey Turner, Initiative for Healthy Schools, College of Education, Boise State University, 1910 University Drive Boise, ID 83725, 1(208) 426-1637, USA. E-mail: lindseyturner1@boisestate.edu
} 
What Does Classroom-based Physical Activity Look Like?

CBPA in elementary schools can take various forms, and many curricula have been developed, tested, and disseminated, such as Take 10!® (Kibbe et al., 2011; Peregrin, 2001), Brain Gym ${ }^{\circledR}$ (Educational Kinesiology Foundation, Santa Barbara, CA, US), and Energizers (Mahar, Kenny, Shields, Scales, \& Collins, 2006a, 2006b). These three programs were among the most commonly reported in a national survey of 640 public US elementary schools in the 2013-14 school year (Turner \& Chaloupka, 2016); however, many other materials are available freely online, and anecdotal reports indicate that it is common for teachers to use a combination of materials, often in conjunction with self-developed activities. Some CBPA strategies involve stopping instruction for several minutes, asking students to stand or move elsewhere in the classroom, and having the teacher or a video lead a guided activity that involves movement. The duration, intensity, and structure of these activities can vary considerably. A more recent development has been the availability of online tools such as GoNoodle ${ }^{\circledR}$ (www.gonoodle.com), which provides a large library of activity videos. While scientific evidence about the extent of usage of this program is not yet available, as of January 2019 the company estimated that it reaches more than 14 million children in classrooms internationally.

The integration of PA directly into instruction through active lessons-either with or without specific curricula-is also growing, and a systematic review has documented the educational benefits of such strategies (Norris, Shelton, Dunsmuir, Duke-Williams, \& Stamakis, 2015). Like the current study, much of the research on CBPA addresses both types of strategies, including stand-alone PA and integrated movement via active lessons.

\section{The Extent of Elementary School Teachers' Use of CBPA}

Despite the emerging evidence about the benefits of CBPA as well as the widespread availability of curricula and activities, the use of these strategies is far from the norm in elementary schools. Nationally-representative data from 640 US public elementary schools surveyed in 2013-14 showed that at 76\% of schools, at least one or more classroom teachers used CBPA (Turner \& Chaloupka, 2016). However, the extent of implementation at those schools was relatively minimal, with administrators estimating that fewer than half of teachers, on average, had ever used CBPA. Thus, it is apparent that the use of CBPA is not yet widespread, warranting further exploration into barriers and opportunities for change.

What Do We Already Know About What Teachers Think of CBPA?

Although a growing amount of literature demonstrates the benefits of CBPA, less work has focused on understanding teachers' experiences with the process of implementing CBPA, including considerations as to why teachers door do not-utilize it. Planning for and implementing CBPA could present a strain on teachers, who already operate under demands from various stakeholders to provide rigorous and individualized instruction while meeting robust standards on a tight schedule. Indeed, prior work has shown that teacher concerns often relate to time pressures and the need to prepare students for standardized testing (Gately, Curtis, \& Hardaker, 2013).

As part of a process evaluation conducted during an intervention to train teachers to use CBPA at 24 schools, Gibson and colleagues (2008) found that although many teachers said they like CBPA, the actual use of these strategies was fairly limited, even among teachers who enjoyed such activities. Other work has documented that while many teachers like the idea in principle, the logistics and real-world pressures of education settings makes implementation challenging (Cothran, Kulinna, \& Garn, 2010; McMullen, Kulinna, \& Cothran, 2014; Webster et al., 2017).

In part due to increased promotion of CBPA by national organizations such as SHAPE America and Association for Supervision and Curriculum Development (ASCD), a growing number of pre-service and in-service teachers are gaining exposure to CBPA in their training and practice. This increasing utilization of CBPA among teachers may lead to a shift in social norms at schools toward promoting a more active and less sedentary culture. However, in-service teachers continue to report systemic environmental barriers to using CBPA. Even after the provision of trainings to instruct classroom teachers on offering PA opportunities to their students, CBPA implementation levels among teachers in real-world contexts (i.e. not in a controlled research intervention) has been sub-optimal (Carlson et al., 2015; Erwin, Beighle, Morgan, \& Noland, 2011). This warrants investigation into additional supports for implementation, including novel approaches, such as peer coaching and resource sharing within the existing school network. Indeed, preliminary evidence on the effects of a supportive implementation climate (including teacher training, technical assistance, support groups, and the provision of resources) shows that it is associated with increased CBPA implementation (Carlson et al., 2017).

Due to the nuanced information required to understand complex issues, many of the prior studies of CBPA have been qualitative in nature, utilizing interviews. These studies have been conducted internationally (Naylor, Macdonald, Zebedee, Reed, \& McKay, 2006; Gately, Curtis \& Hardaker, 2013), and in a variety of school settings in the US (Cothran et al., 2010; McMullen et al., 2014; Vazou \& Skrade, 2014; Webster et al., 2017). Most prior studies have utilized relatively small samples of teachers ranging from eight teachers (Gately, Curtis \& Hardaker, 2013) to 23 teachers (Cothran, Kulinna \& Garn, 2010), although a recent study interviewed 59 classroom teachers (K-8) and specialists at five schools in the Midwest (Dinkel, Schaffer, Snyder, \& Lee, 2017). This prior work has identified consistent themes about teachers' perceived benefits and barriers to using CBPA, ranging from structural issues such as lack of time or space, to leadership issues such as an explicit lack of approval from administrators, to intrapersonal issues such as low perceived competence and motivation. However, most prior studies sampled teachers who are relatively-engaged stakeholders, recruiting teachers who have enough interest in CBPA to volunteer to participate in research. Fewer studies (Carlson et al., 2017; Webster et al., 2017) have quantitatively examined the level of implementation the teachers achieved in relation to their CBPA perceptions. The current study expands the field by employing mixed methods - including interviews and implementation data - and a larger sample of teachers that includes both engaged and unengaged stakeholders.

\section{Theoretical Framework}

In school settings, as in other organizational environments, implementation of evidence-based programs such as CBPA necessitates additional strategies beyond the "train-and-hope" approach (Stokes \& Baer, 1977). With particular relevance to schools is the need for support beyond a single professional development (PD) training at the onset of a school year, if a program is to be successfully implemented. According to the work of Fixsen and colleagues, core components of implementation include practitioner training, coaching on the job, assessing implementation fidelity, and using assessment information to learn and improve performance (Fixsen, Naoom, Blase, \& Friedman 2005). 
Within the Core Implementation Components, Consultation and Coaching fulfills several needs of the teachers, beyond the initial "how-to" provided in PD sessions. These dimensions of coaching include supervision, teaching, the provision of assessment and feedback, and emotional support (Fixsen et al., 2005, p. 44). After the initial PD, these four dimensions of coaching "can help practitioners put the segmented basic knowledge and skills into the whole clinical context" (p. 45). In the case of implementing CBPA ideally a coach would have specialized training in the delivery of CBPA, and dedicate multiple hours per week to coaching-related tasks with each teacher. While some school districts have the resources to employ a school wellness coordinator to fulfill this need, most schools would need to rely on an existing staff member to serve as a leader or champion for CBPA. However, this may not be feasible for one teacher to accomplish, without substantial release time or reallocation of duties, given the time and resource constraints under which teachers and staff at schools typically operate (Hands, 2012). However, relying on the collective strengths of existing personnel and structures at schools to provide these aspects of coaching is one potential approach to support implementation.

School administrators are also critical players in the adoption and maintenance of evidence-based practices, and thus have influence at many stages of implementation. In the Core Implementation Components from Fixsen and colleagues, facilitative administration "provides leadership and makes use of a range of data inputs to inform decision making, support the overall processes, and keep staff organized and focused on the desired clinical outcomes" (Fixsen et al., p. 29). Administrators have a key role in constructing the school environment to support a practice or program of interest. The component of Facilitative Administrative Supports can take the form of creating a culture conducive to implementation, streamlining related processes, providing monetary, material, and personnel resources, monitoring progress, and making their support of the implementation public. Note that in schools, these supports may not all be attended to by an administrator/ principal, but rather distributed across stakeholders.

\section{Need for the Present Study}

In-service teachers continue to report systemic environmental barriers to using CBPA. Leveraging opportunities for collaboration among existing school staff members is one way to potentially address these barriers. Although this concept seems useful for increasing CBPA uptake, research to date has not explored teacher beliefs about the feasibility and utility of these methods. The present study used a qualitative approach to examine elementary school teachers' opinions about support strategies (i.e. coaching and administrative supports) that might improve their ability to implement CBPA. Specifically, the following objectives were explored:

1) What is the potential role of teachers' collaboration time for fulfilling coaching needs in support of CBPA implementation?

2) What is the potential role of each school's $P E$ teacher as a resource for CBPA coaching?

3) What facilitative administrative supports do teachers perceive they need for successful CBPA implementation?

\section{Method}

These data were gathered as a part of a study that examined the implementation of CBPA at two elementary schools during the 2016-2017 school year. The study was approved by the Institutional Review Board at Boise State University.

\section{School Contexts}

The demographic characteristics of schools are presented in Table 1. To preserve privacy, not all identifying data are provided in the table. Both schools were situated in rural areas and served high-need communities, with student enrollments ranging from $\sim 350$ to $\sim 500$ students in kindergarten through grade 5 . One of the schools had more experienced teachers, whereas at the other school half of the teachers were early-career professionals (fewer than five years in the classroom).

Table 1. Characteristics of Participating Elementary Schools

\begin{tabular}{lrr}
\hline & School 1 & School 2 \\
\hline Student characteristics & & \\
\hline \% White non-Hispanic/Latino students & $50-60 \%$ & $40-50 \%$ \\
\hline \% Hispanic/Latino students & $30-40 \%$ & $50-60 \%$ \\
\hline $\begin{array}{l}\text { \% students eligible for free/reduced-priced } \\
\text { meals }\end{array}$ & $60-70 \%$ & $80-90 \%$ \\
\hline Title 1 status & Yes & Yes \\
\hline Teacher characteristics & 16 & 20 \\
\hline $\begin{array}{l}\text { Number of self-contained classroom } \\
\text { teachers }\end{array}$ & 15 years & 5.5 years \\
\hline Median number of years teaching & 1 to 32 & 1 to 20 \\
\hline Range of years teaching & 4 & 10 \\
\hline Number of early-career teachers (<5 years) & & \\
\hline Note. To preserve school privacy, demographic characteristics are shown in
\end{tabular}
Note. To preserve school privacy, demographic characteristics are shown in decile ranges.

\section{Professional Development for Implementing CBPA}

At these two schools, all classroom teachers attended a PD session about CBPA led by two research team members who were formerly licensed teachers in $\mathrm{K}-12$ public schools. Separate sessions were conducted for K-2 teachers and for grade 3-5 teachers to create an optimal group size for comfort and interaction, and to customize examples to be developmentally-appropriate for students of differing ages. The sessions were 90 minutes long. During the sessions, the scientific evidence about the academic and health benefits of CBPA was discussed, demonstrations were provided, and teacher questions were addressed. Each teacher was given an Energizers booklet, (Mahar, Kenny, Shields, Scales, \& Collins, 2006a, 2006b) which included 22 activities for grades K-2 and 26 activities for grades 3-5. Teachers were also encouraged to use other resources, including Go Noodle ${ }^{\circledR}$, other online tools, or personally-created activities. Teachers were subsequently asked to implement CBPA over the following 12 weeks, and track the extent of their CBPA usage through weekly logs provided by the research team. These printed logs provided spaces for teachers to document the duration and frequency of CBPA use.

\section{Data Collection}

At the end of each week during the implementation period, research staff collected teachers' CBPA logs. After ten weeks, semi-structured interviews (Merriam, 2009) were scheduled with all teachers at both of the schools. Teachers were offered the option of an individual interview, or a group interview as a grade-level team. A total of 15 interviews were conducted, with 35 teachers. When interviews were conducted as grade-level teams, efforts were made to elicit responses from every teacher. Interviews were conducted on school grounds, either before or after school, or during teachers' prep time. Interviews were conducted by the first or third author. The duration 
of interviews ranged from 9 minutes to 26 minutes (mean $=17$ minutes). While several interviews were fairly brief due to receiving minimal feedback from teachers, some teachers provided extensive input. Interview questions included: "To what extent might collaboration time be used at schools for teachers to share strategies among themselves?," "To what extent might the PE teacher at a school be a resource for classroom teachers?" and "What types of things can administrators do to support teachers in using CBPA?"

\section{Data Analysis}

We calculated descriptive statistics to provide a summary of average CBPA usage across all teachers in the study. After transcribing the audiotaped interviews verbatim, we then conducted structural coding of the data (Saldaña, 2015) by reading through each document and applying thematic phrases to segments of data that corresponded to research questions. We then refined coding categories through iterative rounds of focused coding (Saldaña 2015). The first two authors began reviewing this framework of categories during the early stages of analysis, gradually incorporating sub-themes, which continued until no new themes emerged. Throughout this process, authors coded portions of the data independently then met to resolve discrepancies. All transcripts were then revisited by the first three authors, which allowed the team to confirm the appropriateness of the codes, develop themes (Saldaña \& Omasta, 2017) and ascertain the representativeness of themes across participants and schools.

\section{Results}

Data from teachers' CBPA logs revealed that most teachers were able to implement some CBPA. Across all teachers, the average number of activities provided to students per day was .56 activities (approximately one activity every two days), with an average of 34 activities provided per teacher over the 12 weeks, or about three per week. Five teachers provided one or fewer activities per week on average, and those teachers were located in both schools (two at one school and three at another). Implementation was similar across schools, with one school totaling 619 activities across all teachers, while the other school totaled 632 activities. The average duration of activities provided was 6.7 minutes.

The interviews explored potential approaches to improving the process of CPBA implementation, including the Coaching components and Facilitative Administrative Supports described within Fixsen et al.'s (2005) theoretical framework. The data revealed four themes. Note that the Supervision and Teaching components in the Coaching component from Fixsen et al.'s framework did not arise from the data.

\section{Coaching and Consultation}

The first theme that arose was that teachers were not as interested in feedback on their own actions or implementation as they were interested in feedback about particuIar CBPA strategies and activities. Teachers suggested that knowing what their peers were doing, such as in the form of a bulletin board posting CBPA activities that they had tried during the week, would have been a helpful form of knowledge sharing. Many teachers noted that quick hallway-conversation recommendations from peers can be useful feedback, such as "Hey, I did this one. This one was a dud, or this one was a hit," or listing particular GoNoodle ${ }^{\circledR}$ activities that they had used. In terms of how to structure the CBPA within their busy days, another teacher stated, "When you hear it from somebody you know, saying like 'Yeah, this is when I do it' really helps and I think you're more willing to try it." More than anything, teachers saw their classroom-teaching peers as experts on exactly what will work well within the classroom.

All teachers at these schools had a block of time once per week allocated for peer collaboration; we inquired how that time was used, and whether sharing CBPA strategies would be an appropriate use of that time. Teacher responses were mixed. Some agreed that it could be appropriate, because they perceive their peers to be credible sources of information about what works and what doesn't work. However, some teachers felt that their formal collaboration time was already so busy that it might not be practical. On the other hand, some teachers noted that while collaboration time is typically very tight, there is the possibility of a quick conversation to discuss what is working well for each teacher in terms of CPBA. The interviewer notes that were used to document subjective interviewer perceptions about the data indicated that some grade-level teams were particularly collaborative and supportive of one another, and often these were the teachers who indicated that they would value the sharing of strategies among their team, whereas less-cohesive teams were not eager to use collaboration time for this purpose.

A second theme in the area of assessment and feedback was that for most teachers, feedback about CBPA from the PE teacher was either not viable or not the optimal choice for implementation support. Although teachers spoke positively of instances in which the PE teacher had collaborated with them on particular topics or activities such as combining motion with math facts or spelling words, the concept of PE teachers providing classroom teachers with tips about integrating CBPA was not enthusiastically supported. Even though it was widely recognized that the PE teacher would be knowledgeable in PA and CBPA and that they would be helpful if teachers asked questions, as one teacher asserted, "I would go to my team before [the PE teacher], just to see what they're doing and how they're incorporating it into their classroom... it's a little bit more realistic and concrete for me to be able to follow." Some teachers expressed concern that the PE teacher would not understand the classroom context; they mentioned that the PE teacher might use activities that are "too disruptive for what we would need" or that PE teachers may not take into account the limited space, desks, and chairs within the classroom.

Other classroom teachers stated that there was no time for this type of collaboration; either the PE teacher was too busy (one of the PE teachers was only at her school halftime), or the classroom teachers were too busy to have truly work together on CPBA implementation. Finally, a number of teachers noted that CPBA is a fairly simple concept and does not require further feedback or assistance from an 'expert' such as a PE teacher. Concerning GoNoodle ${ }^{\circledR}$ activities, one teacher said, "It's pretty plug and go," while a second teacher using the Energizers activities said, “We have the book... I don't know if we need her [the PE teacher]." Another teacher quipped, "I can figure out how to take a one minute brain break." This is not to say that classroom teachers universally dismissed the idea of receiving CPBA support from PE teachers. Two grade teams at one of the schools stated that having the PE teacher come into the classroom to model an activity would be "encouraging" and that "it absolutely is important that they [students] see that your PE teacher is just as much a part of the classroom as a pencil and paper." Overall, there seemed to be some promise in engaging PE teachers as implementation experts, but many additional questions remain about the logistics of making this process innovation work smoothly, and what structural or scheduling changes might be needed for this type of support. 


\section{Facilitative Administrative Supports}

Strong themes emerged around administrative support, either in terms of what administrative factors had been particularly helpful as they worked through the process of implementation, or what teachers felt they needed to be successful. The first theme that arose from the data in this area was that teachers appreciate and/or need assurance from administrators that it is acceptable to have a classroom that is full of moving children and that is also acceptable to take some time away from instruction to support CPBA. As one teacher noted, "I feel like our administrator... recognizes the need of our kids-they just can't focus and they need movement... She has walked in when we're in the middle of a video or an activity and she's like 'Good job guys!'” Another teacher explained how having explicit feedback during evaluations was particularly helpful:

...during my observation this year my class was flat, and so did a brain break during the observation, and she put in the notes, like "Nice read of your class, good job using a brain break here." So she showed a very positive reaction to seeing that happen in the class.

However, while some teachers at both schools felt supported, others were less certain about their administrator's position and noted that the "mixed messages" between focusing on instructional time versus taking time for CBPA was a barrier to implementation: "Maybe letting us know what is okay. Because I think that there's some times when they're such a stickler on being on schedule." And another commented: "You know, there's some fear if the principal walks in... are we going to get in trouble because all of our kids are laying on the floor at the end of their yoga story?" Similarly, another teacher stated,

They [the principal] come in during my thirty second break when the kids are running up the walls... I'm like, "I promise, I really am teaching.' Like I feel like I have to apologize, and I don't want to have to do that.

Finally, a teacher summed up this theme by stating,

I think there is a little bit of a fear of having a classroom that's moving all the time, or that's a little bit louder, or is walking around, or that you feel like that maybe some people will feel like your class is wild or crazy... You feel like you should have a quiet classroom, you should having them all sitting in their desks, you know that's your ideal, and so I think having an administrator that supports the facts that some of your kids are jumping, some of your kids are sitting, [is important].

A second theme that arose from the data in terms of support was that in addition to assurances from administrators that CPBA is acceptable, many teachers wanted explicit gestures of support. Suggestions for these gestures included reminders in weekly updates to "do some physical activity," incentives for doing CPBA for a certain amount of time, morning announcements along the lines of, "Let's make sure we Energize... I challenge everyone to get up and move... I tried the California Dreaming activity yesterday. I challenge every class to do that today," and direct emails stating that GoNoodle $\AA$ and similar activities are encouraged in the classroom. Given that time was noted as a major barrier, teachers also gravitated towards the suggestion that explicit support could be shown through the scheduling of CBPA into the school day. For example, one teacher stated that some extra time added into the schedule would be great support: "If it's [CPBA] scheduled in then you have time for it because you know it's a priority."

\section{Discussion}

Teachers implementing CBPA in the typical classroom context (i.e. not delivered by trained research staff) can struggle to provide daily activities to their students, even when PD and resources, such as activity suggestions, are provided (Carlson et al., 2015; Erwin et al., 2011). We found that teachers in our study, who were given a short PD, provided resources, and asked to implement CBPA daily throughout the fall semester, also encountered barriers to CBPA implementation. On average, teachers did successfully implement some CBPA, providing about five minutes of CBPA per day on average. While some level of implementation is certainly better than none, providing students ten minutes per day of CBPA is currently regarded as best practice (CDC, 2018). National rates of CBPA implementation vary somewhat from study to study (CDC, 2015; Turner \& Chaloupka, 2016), but also estimate that teachers across the US are not meeting this guideline. In much of the CBPA literature, teachers value CBPA as a practice (Dinkel, Lee, \& Schaffer, 2017; Foran, Mannion, \& Rutherford, 2017), but barriers to implementation remain a problem (McMullen et al., 2014; Stylianou et al., 2016; Webster et al., 2017). Overall, many of resources available to teachers and schools (e.g., through an internet search for classroom physical activity programs) do not provide within their materials an extensive amount of evidence-based supports for implementation (Calvert et al., in press). Thus, while utilizing CBPA is becoming increasingly viewed as a best practice, and included in state-level school wellness policies in almost half of states in the US (Chriqui et al. 2019, p. 8) and abroad (Weatherson, Locke, \& June, 2018), the investigation into proper implementation supports for this practice is still a developing field. This study examined the feasibility of several novel approaches to improve CBPA implementation through interviewing a sample of teachers who had been implementing CBPA for 12 weeks.

Despite the evidence base to support the components from Fixsen et al.'s (2005) implementation framework, two of the pieces within the coaching component were not explicitly discussed by teachers as necessary to implement CBPA. The analysis of teacher interviews revealed that themes related to the Supervision component were non-existent; thus, the majority of teachers did not seem eager to have tailored, expert oversight or feedback. Teachers spoke to the potential benefit of having their peers give them reminders, although it was still brought up relatively rarely. Additionally, while their grade-level collaboration time was seen as a viable outlet for these types of discussions - particularly in terms of recommendations for certain activities and strategies - in most cases, teachers did not view the discussion of CBPA as a formative need during their collaborative time. Teachers discussed that they did view their peers as content experts in many things, and would take advice regarding CBPA, often this type of sharing occurred informally, such as after school time or during transitions or preparation periods. Given the relatability of peers (versus the PE teacher) as well as the established collaboration time, we do wonder if collective goal setting around CBPA - rather than simply discussing activities they liked or what they would recommend - during collaboration time may yield increased CBPA. Voelkel and Chrispeels (2017), in their study of PLCs, found that collective goal setting and focusing on results supported teacher collective efficacy in terms of supporting students via instruction; we see these results as being potentially transferable to supporting CBPA.

Although teachers conveyed an openness and receptivity to the idea of collaboration with the PE teacher, in most cases, we interpreted these opinions as conferring a "thanks but no thanks" sentiment. Certainly a few outliers were eager for this type of knowledge-sharing from the PE teacher, but most teachers felt that they were confident in their ability to implement CBPA on their own. There has been some consideration of PE teachers as school physical activity directors (Castelli \& Beighle, 2007), 
or individuals who coordinate and motivate the offering of school PA in line with comprehensive school physical activity recommendations. However, this work, as well as previous research (Webster, Beets, Weaver, Vazou, \& Russ, 2015; Wenner, Tucker, Calvert, Johnson, \& Turner, 2019), has shown that this is perhaps an optimistic view of the role of PE teacher as the most well-positioned promoter of school-wide PA. However, other leaders in the school, such as a charismatic teacher leader, or even a parent or school administrator, could be considered to play this type of role (Carson, Pulling, Wolak, Castelli, \& Beighle, 2014).

Teachers in this study expressed that CBPA implementation was possible, and felt that they had the tools to implement it, if not the explicit "permission" from their school leader. As demonstrated by the teachers' comments, verbal and written support, particularly from administrators, can go a long way toward helping teachers feel more confident about CBPA. In fact, a display of administrative support was the most frequently discussed method of increasing implementation of CBPA. This corroborates findings from previous work examining CBPA implementation. In their study which utilized an expert panel to assess implementation of school-based PA programs, Lau and colleagues identified administrator support as the strongest predictor of PA implementation within an organization, estimating that an initiative with a high level of support would be 8.75 times more likely to be implemented (Lau, Wandersman, \& Pate, 2016). As such, conveying the academic and behavioral benefits of CBPA to district and school-level leaders is important. In another review of PA intervention implementation in the school context, lack of time was found as the most commonly reported barrier among teachers (Naylor et al., 2015), followed by resource access and lack of supportive school culture for PA. School administrators have great influence over school culture (Leithwood \& Jantzi, 1990), so providing small supports, over time, may facilitate sustained implementation. Administrators could provide a solution to time-related barriers through scheduling activity breaks or physically active transition times into their school's calendar which details teacher daily agendas minute to minute. Encouraging teachers to implement CBPA through email reminders, staff meetings, and announcements could also be an effective way for administrators to show teachers explicit support, while positively influencing the school culture towards PA.

\section{Strengths and Limitations}

The use of tracking log data to measure implementation fidelity, combined with teacher attitudes regarding implementation supports, allowed for interpretation of teacher opinions in light of their implementation success, which we view as a strength of this study. However, we were unable to link implementation to interview feedback at teacher level (rather it was done at the school level), since group interviews were done for a majority of teachers and names were not collected for purposes of anonymity. Further, the self-reported teacher CBPA tracking logs were taken at face value, thus potentially susceptible to "desirability bias," despite the fact that we encouraged teachers to be candid in their responses. However, we believe that the combination of the quantitative and qualitative data allow us to learn more about teachers' journeys of CBPA implementation and the (mis)match between actual implementation of CBPA and the perceptions surrounding supports needed for successful CBPA implementation.

\section{Conclusions}

With the increasing amount of recent literature outlining the benefits of school-day PA, it has become clear that the question is not "Should teachers implement CBPA?" but rather "How can educational stakeholders support teachers in implementing CBPA?" Results of this study demonstrate that CBPA implementation is viewed by elementary teachers as achievable in today's complex educational context, and beyond that, our results reveal that extensive PD may not be necessary for classroom teachers to feel comfortable in implementing CBPA on a regular basis, as most teachers feel CBPA is relatively easy to execute. However, implementation at recommended levels, as well as ongoing implementation, requires more substantial support. Our results suggest that feedback on activities (rather than teachers' implementation of those activities) as well as explicit support for CBPA may be the levers for successful and sustained CBPA implementation. Administrators, PE teachers, or other PA champions at schools can encourage teachers to implement CBPA or direct them to the many 'tried and true' resources available online and in print. Administrators specifically should play an active role in assessing CBPA use, and providing positive feedback on teacher assessments and staff meetings regarding CBPA use. This study suggests that while many potential avenues exists for knowledge-sharing within the school can be utilized, the most universal theme is that teachers want to feel supported by their school leader in their choice to implement CBPA.

\section{Acknowledgements}

The work described here was supported by the Institute of Education Sciences, US Department of Education, through grant R305A150277 to Boise State University. The opinions expressed are those of the authors and do not represent views of the Institute of Education Sciences or the US Department of Education.

\section{References}

American Alliance for Health, Physical Education, Recreation and Dance (2006). Recess for Elementary School Students. A Position Paper from the National Association for Sport and Physical Education. Reston, VA: American Alliance for Health, Physical Education, Recreation and Dance. Retrieved from https://files. eric.ed.gov/fulltext/ED497155.pdf

Bartholomew, J. B., \& Jowers, E. M. (2011). Physically active academic lessons in elementary children. Preventive Medicine, 52 Suppl 1, S51-54. https://doi. org/10.1016/j.ypmed.2011.01.017

Burns, R. D., Brusseau, T. A., Fu, Y., Myrer, R. S., \& Hannon, J. C. (2016). Comprehensive school physical activity programming and classroom behavior. American Journal of Health Behavior, 40(1), 100-107. https:// doi.org/10.5993/AJHB.40.1.11

Calvert, H.G., Lane, H.G., Bejarano, C.M., Snow, K., Hoppe, K., Alfonsin, N., Turner, L., Carlson, J.A (2018). An evaluation of the coverage of theoretically based implementation factors in disseminated classroom physical activity programs. Translational Behavioral Medicine. https://doi.org/10.1093/tbm/ iby 134

Carlson, J. A., Engelberg, J. K., Cain, K. L., Conway, T. L., Geremia, C., Bonilla, E., ... Sallis, J. F. (2017). Contextual factors related to implementation of classroom physical activity breaks. Translational Behavioral Medicine, 7(3), 581-592. https://doi.org/10.1007/ s13142-017-0509-x 
Carlson, J. A., Engelberg, J. K., Cain, K. L., Conway, T. L., Mignano, A. M., Bonilla, E. A., ... Sallis, J. F. (2015). Implementing classroom physical activity breaks: Associations with student physical activity and classroom behavior. Preventive Medicine, 81, 67-72. https://doi.org/10.1016/j.ypmed.2015.08.006

Carson, R. L., Pulling, A. C., Wolak, M., Castelli, D. M., \& Beighle, A. (2014). Facilitators and inhibitors of the director of physical activity program and comprehensive school physical activity program implementation. Research Quarterly for Exercise and Sport, 85(S1), 56-56.

Castelli, D. M., \& Beighle, A. (2007). The physical education teacher as school activity director. Journal of Physical Education, Recreation \& Dance, 78(5), 25-28.

Centers for Disease Control and Prevention. (2013). Comprehensive school physical activity programs: A guide for schools. Atlanta, GA: Centers for Disease Control and Prevention, U.S. Department of Health and Human Services. Retrieved from http:// www.cdc.gov/healthyschools/physicalactivity/ pdf/13_242620-A_CSPAP_SchoolPhysActivityPrograms_Final_508_12192013.pdf

Centers for Disease Control and Prevention. (2015). Results from the Sschool health policies and practices study 2014. Atlanta, GA: Centers for Disease Control and Prevention, U.S. Department of Health and Human Services. Retrieved from https://www.cdc. gov/healthyyouth/data/shpps/pdf/SHPPS-508-final_101315.pdf

Centers for Disease Control and Prevention. (2018). Strategies for classroom physical activity in schools. Atlanta, GA: Centers for Disease Control and Prevention, U.S. Department of Health and Human Services. Retrieved from https://www.cdc.gov/ healthyschools/physicalactivity/pdf/Classroom PAStrategies_508.pdf

Centers for Disease Control and Prevention. (2010). The association between school-based physical activity, including physical education. Atlanta, GA: Centers for Disease Control and Prevention, U.S. Dept. of Health and Human Services. Retrieved from https://www.cdc.gov/healthyyouth/health_and_ academics/pdf/pa-pe_paper.pdf

Chriqui, J., Stuart-Cassel, V., Piekarz-Porter, E., Temkin, D., Lao, K., Steed, H., ... Gabriel, A (2019). Using state policy to create healthy schools: coverage of the Whole School, Whole Community, Whole Child Framework in state statutes and regulations school year 2017-2018. Bethesda, MD: Child Trends (Publication \#201909). Retrieved from https://www.childtrends.org/ wp-content/uploads/2019/01/WSCCStatePolicyReportSY2017-18_ChildTrends_January2019.pdf

Cothran, D. J., Kulinna, P. H., \& Garn, A. C. (2010). Classroom teachers and physical activity integration. Teaching and Teacher Education, 26(7), 1381-1388.

Dinkel, D. M.; Lee, J-M.; Schaffer, C. (2017). Examining the knowledge and capacity of elementary teachers to implement classroom physical activity breaks. International Electronic Journal of Elementary Education, 9(1), 182-196.
Dinkel, D. M., Schaffer, C., Snyder, K., \& Lee, J. M. (2017). They just need to move: Teachers' perception of classroom physical activity breaks. Teaching and Teacher Education, 63, 186-195. https://doi. org/10.1016/j.tate.2016.12.020

Donnelly, J. E., \& Lambourne, K. (2011). Classroom-based physical activity, cognition, and academic achievement. Preventive Medicine, 52 Suppl 1, S36-42. https://doi.org/10.1016/j.ypmed.2011.01.021

Erwin, H. E., Beighle, A., Morgan, C. F., \& Noland, M. (2011). Effect of a low-cost, teacher-directed classroom intervention on elementary students' physical aActivity. Journal of School Health, 81(8), 455-461. https://doi.org/10.1111/j.1746-1561.2011.00614.x

Fixsen, D. L., Naoom, S. F., Blase, K. A., \& Friedman, R. M. (2005). Implementation research: a synthesis of the literature. Tampa, FL: University of South Florida, Louis de la Parte Florida Mental Health Institute, The National Implementation Research Network (FHMI Publication \#231).

Foran, C. A., Mannion, C.; Rutherford, G. (2017). Focusing elementary students with active classrooms: exploring teachers' perceptions of self-initiated practices. International Electronic Journal of Elementary Education, 10(1), 61-69.

Gately, P., Curtis, C., Hardaker, R., McBride, N., McKay, M., Sumnall, H., \& Evans, D. (2013). An evaluation in UK schools of a classroom-based physical activity programme-TAKE 10!®: A qualitative analysis of the teachers' perspective. Education and Health, 31(4), 72-78

Gibson, C. A., Smith, B. K., DuBose, K. D., Greene, J. L., Bailey, B. W., Williams, S. L., ... \& Mayo, M. S. (2008). Physical activity across the curriculum: year one process evaluation results. International Journal of Behavioral Nutrition and Physical Activity, 5(1), 36. https://doi.org/10.1186/1479-5868-5-36

Grieco, L. A., Jowers, E. M., Errisuriz, V. L., \& Bartholomew, J. B. (2016). Physically active vs. sedentary academic lessons: A dose response study for elementary student time on task. Preventive Medicine, 89, 98103. https://doi.org/10.1016/j.ypmed.2016.05.021

Hands, C. M. (2012). Supporting teacher leadership for partnerships. In S. Auerbach (Ed.), School leadership for authentic family and community partnerships (pp. 173-192). New York, NY: Taylor \& Francis.

Hollar, D., Messiah, S. E., Lopez-Mitnik, G., Hollar, T. L., Almon, M., \& Agatston, A. S. (2010). Effect of a twoyear obesity prevention intervention on percentile changes in body mass index and academic performance in low-income elementary school children. American Journal of Public Health, 100(4), 646-653. https://doi.org/10.2105/AJPH.2009.165746

Institute of Medicine (2013). Educating the student body: Taking physical activity and physical education to school. Washington, D.C.: National Academies Press. 
Katzmarzyk, P. T., Denstel, K. D., Beals, K., Bolling, C., Wright, C., Crouter, S. E., ... Sisson, S. B. (2016). Results From the United States of America's 2016 Report Card on Physical Activity for Children and Youth. Journal of Physical Activity and Health, 13(11 Suppl 2), S307-S313. https://doi.org/10.1123/ jpah.2016-0321

Kibbe, D. L., Hackett, J., Hurley, M., McFarland, A., Schubert, K. G., Schultz, A., \& Harris, S. (2011). Ten Years of

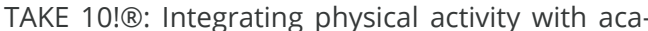
demic concepts in elementary school classrooms. Preventive Medicine, 52, S43-S50. https://doi. org/10.1016/j.ypmed.2011.01.025

Lau, E. Y., Wandersman, A. H., \& Pate, R. R. (2016). Factors influencing implementation of youth physical activity interventions: An expert perspective. Translational Journal of the American College of Sports Medicine, 1(7), 60-70. https://doi.org/10.1249/ TJX.0000000000000006

Leithwood, K., \& Jantzi, D. (1990). Transformational leadership: How principals can help reform school cultures. School Effectiveness and School Improvement, 1(4), 249-280.

Lewallen, T. C., Hunt, H., Potts-Datema, W., Zaza, S., \& Giles, W. (2015). The Whole School, Whole Community, Whole Child Model: A new approach for improving educational attainment and healthy development for students. Journal of School Health, 85(11), 729739. https://doi.org/10.1111/josh.12310

Mahar, M. T. (2011). Impact of short bouts of physical activity on attention-to-task in elementary school children. Preventive Medicine, 52 Suppl 1, S60-64. https://doi.org/10.1016/j.ypmed.2011.01.026

Mahar, M. T., Kenny, R. K., Shields, A. T., Scales, D. P., \& Collins, G. (2006a). Energizers Classroom-based Physical Activities 3-5: The way teachers integrate physical activity with academic concepts. Retrieved from http:// thescholarship.ecu.edu/handle/10342/5945

Mahar, M. T., Kenny, R. K., Shields, A. T., Scales, D. P., \& Collins, G. (2006b). Energizers: Classroom-based Physical Activities K-2. Retrieved from http://thescholarship.ecu.edu/handle/10342/5943

Mahar, M. T., Murphy, S. K., Rowe, D. A., Golden, J., Shields, A. T., \& Raedeke, T. D. (2006). Effects of a classroom-based program on physical activity and ontask behavior. Medicine and Science in Sports and Exercise, 38(12), 2086-2094.

McMullen, J., Kulinna, P., \& Cothran, D. (2014). Physical activity opportunities during the school day: classroom teachers' perceptions of using activity breaks in the classroom. J Teach Phys Educ, 33(4), 511-27.

Merriam, S. B. (2009). Qualitative Research: a guide to design and interpretation. San Francisco: Jos-Sey-Bass.

Norris, E., Shelton, N., Dunsmuir, S., Duke-Williams, O., \& Stamatakis, E. (2015). Physically active lessons as physical activity and educational interventions: a systematic review of methods and results. Preventive Medicine, 72, 116-125, https://doi. org/10.1016/j.ypmed.2014.12.027
Naylor, P.-J., Macdonald, H. M., Zebedee, J. A., Reed, K. E., \& McKay, H. A. (2006). Lessons learned from Action Schools! BC-An 'active school' model to promote physical activity in elementary schools. Journal of Science and Medicine in Sport, 9(5), 413-423. https:// doi.org/10.1016/j.jsams.2006.06.013

Pate, R. R., Davis, M. G., Robinson, T. N., Stone, E. J., McKenzie, T. L., Young, J. C., ... Council on Cardiovascular Nursing. (2006). Promoting physical activity in children and youth: a leadership role for schools: a scientific statement from the American Heart Association Council on Nutrition, Physical Activity, and Metabolism (Physical Activity Committee) in collaboration with the Councils on Cardiovascular Disease in the Young and Cardiovascular Nursing. Circulation, 114(11), 1214-1224. https://doi. org/10.1161/CIRCULATIONAHA.106.177052

Peregrin, T. (2001). Take 10!: classroom-based program fights obesity by getting kids out of their seats. Journal of the Academy of Nutrition and Dietetics, 101(12), 1409.

Rasberry, C. N., Lee, S. M., Robin, L., Laris, B. A., Russell, L. A., Coyle, K. K., \& Nihiser, A. J. (2011). The association between school-based physical activity, including physical education, and academic performance: A systematic review of the literature. Preventive Medicine, 52, Supplement, S10-S20. https://doi.org/10.1016/j.ypmed.2011.01.027

Saldaña, J. (2015). The coding manual for qualitative researchers. Thousand Oaks, CA: Sage.

Saldaña, J., \& Omasta, M. (2017). Qualitative research: Analyzing life. Thousand Oaks, CA: Sage Publications.

Singh, A. S., Saliasi, E., Berg, V. van den, Uijtdewilligen, L., Groot, R. H. M. de, Jolles, J., ... Chinapaw, M. J. M. (2018). Effects of physical activity interventions on cognitive and academic performance in children and adolescents: a novel combination of a systematic review and recommendations from an expert panel. British Journal of Sports Medicine. https://doi. org/10.1136/bjsports-2017-098136

Society of Health and Physical Educators. (2013). Comprehensive school physical activity programs: Helping all students log 60 minutes of physical activity each day [position statement]. Reston, VA: Society of Health and Physical Educators. Retrieved from http://www. shapeamerica.org/advocacy/positionstatements/ $\mathrm{pa/upload/Comprehensive-School-Physical-Ac-}$ tivity-Programs-Helping-All-Students-Log-60-Minutes-of-Physical-Activity-Eeach-Day.pdf

Society of Health and Physical Educators. (2015). The essential components of physical education. Reston, VA: Society of Health and Physical Educators. Retrieved from http://www.shapeamerica.org/upload/TheEssentialComponentsOfPhysicalEducation.pdf

Stokes, T. F., \& Baer, D. M. (1977). An implicit technology of generalization. Journal of Applied Behavior Analysis, 10(2), 349-367. 
Stylianou, M., Kulinna, P. H., van der Mars, H., Mahar, M. T., Adams, M. A., \& Amazeen, E. (2016). Before-school running/walking club: Effects on student on-task behavior. Preventive Medicine Reports, 3, 196-202. https://doi.org/10.1016/j.pmedr.2016.01.010

Tremblay, M. S., LeBlanc, A. G., Kho, M. E., Saunders, T. J., Larouche, R., Colley, R. C., ... Gorber, S. C. (2011). Systematic review of sedentary behaviour and health indicators in school-aged children and youth. International Journal of Behavioral Nutrition and Physical Activity, 8, 98. https://doi. org/10.1186/1479-5868-8-98

Tudor-Locke, C., Lee, S. M., Morgan, C. F., Beighle, A., \& Pangrazi, R. P. (2006). Children's pedometer-determined physical activity during the segmented school day. Medicine and Science in Sports and Exercise, 38(10), 1732-1738. https://doi.org/10.1249/01. mss.0000230212.55119.98

Turner, L., \& Chaloupka, F. J. (2016). Reach and implementation of physical activity breaks and active lessons in elementary school classrooms. Health Education \& Behavior: The Official Publication of the Society for Public Health Education, 44(3), 370-375. https://doi. org/10.1177/1090198116667714

Turner, L., Chaloupka, F. J., \& Slater, S. J. (2012). Geographic variations in elementary school-based physical activity practices. Journal of School Health, 82(7), 307-310. https://doi.org/10.1111/j.17461561.2012.00703.x

Vazou, S., \& Skrade, M. (2014). Teachers' reflections from integrating physical activity in the academic classroom. Research Quarterly for Exercise and Sport, 85(S1), A38.

Voelkel Jr., R. H., \& Chrispeels. J. H. (2017) Understanding the link between professional learning communities and teacher collective efficacy. School Effectiveness and School Improvement, 28(4), 505-526. https://doi.org/10.1080/09243453.2017.1299015

Weatherson, K. A., Locke, S. R., \& Jung, M. E. (2018). Exploring the effectiveness of a school-based physical activity policy in British Columbia, Canada: a mixed-methods observational study. Translational Behavioral Medicine, 9(2), 246-255.

Webster, C. A., Russ, L., Vazou, S., Goh, T. L., \& Erwin, H. (2015). Integrating movement in academic classrooms: understanding, applying and advancing the knowledge base. Obesity Reviews: An Official Journal of the International Association for the Study of Obesity, 16(8), 691-701. https://doi.org/10.1111/ obr.12285

Webster, Collin A., Zarrett, N., Cook, B. S., Egan, C., Nesbitt, D., \& Weaver, R. G. (2017). Movement integration in elementary classrooms: Teacher perceptions and implications for program planning. Evaluation and Program Planning, 61, 134-143. https://doi. org/10.1016/j.evalprogplan.2016.12.011

Webster, Collin Andrew, Beets, M., Weaver, R. G., Vazou, S., \& Russ, L. (2015). Rethinking recommendations for implementing comprehensive school physical activity programs: a partnership model. Quest, 67(2), 185-202. https://doi.org/10.1080/00336297.2015. 1017588
Wenner, J. A., Tucker, K. M. B., Calvert, H. G., Johnson, T. G., \& Turner, L. (2019). Social capital: a key ingredient in the development of physical activity leadership. Journal of Teaching in Physical Education, 38(3), 241 251. https://doi.org/10.1123/jtpe.2018-0057 